\title{
FAZENDO E APRENDENDO: a criação de um software didático como ferramenta complementar no processo de ensino e aprendizado em contabilidade
}

\author{
Cíntia Lisiane da S. Renz ${ }^{1}$, Larissa D. C. Euzebioº ${ }^{2}$ João Miguel E. Bohn ${ }^{3}$ \\ ${ }^{1}$ Campus Osório - Instituto Federal de Educação, Ciência e Tecnologia do Rio Grande \\ do Sul (IFRS) - Osório - RS - Brazil \\ ${ }^{2}$ Centro Universitário Cenecista de Osório (UNICNEC) - Osório - RS - Brazil \\ ${ }^{3}$ Campus Farroupilha - Instituto Federal de Educação, Ciência e Tecnologia do Rio \\ Grande do Sul (IFRS) - Farroupilha - RS - Brazil \\ cintia.renz@osorio.ifrs.edu.br, larissa.dce@gmail.com, \\ joao.bohnefarroupilha.ifrs.edu.br
}

\begin{abstract}
This narrative experience report aimed to narrate the experience of building a didactic bookkeeping tool based on a research project carried out at a campus of a Federal Institute of Education, Science and Technology. The tool was developed by volunteers with the guidance of the campus accounting teacher. The tool in the form of online software was conceived from the provocation of students who sought more technological ways to carry out bookkeeping activities. The analysis carried out by the project team during the software utilization stage revealed that the software can be used as a complementary learning strategy, in view of the acceptance and greater engagement of the students in the discipline after the implementation.
\end{abstract}

Resumo. Este relato de experiência em forma de narrativa teve como objetivo narrar a experiência da construção de uma ferramenta didática de escrituração contábil a partir de um projeto de pesquisa realizado em um campus de um Instituto Federal de Educação, Ciência e Tecnologia. A ferramenta foi desenvolvida por bolsistas voluntários com a orientação da professora de contabilidade do campus. As análises realizadas pela equipe do projeto durante a etapa de utilização do software revelaram que o software pode ser utilizado como uma estratégia complementar de aprendizagem, tendo em vista a aceitação e o maior engajamento dos alunos na disciplina após a implementação da ferramenta.

\section{Introdução}

Para Clandinin e Connelly (2011, p. 48) "a narrativa é o melhor modo de representar e entender a experiência". Permite autoavaliar as estratégias adotadas, criar memórias sobre a construção das coisas, identificar as lacunas, os benefícios, possibilitando até, quem sabe, um reposicionamento do próprio sujeito epistêmico. 
"Professora!!! não tem um sistema que nos ajude a fazer isso? No escritório que minha tia trabalha é tudo no computador! São muitos T(zinhos) para fazer no caderno! Só saberemos se acertamos todos os lançamentos quando somarmos tudo no final?"

Essas provocações e indagações, aliadas ao potencial de um campus de um Instituto Federal de Educação, Ciência e Tecnologia, mais a expertise técnica dos docentes da área da informática e contabilidade e a colaboração voluntária de alunos, possibilitaram o desenvolvimento de um projeto de pesquisa que teve como objetivo a materialização de uma ferramenta de apoio ao ensino de contabilidade.

\section{A construção do software}

O estudo e a construção da ferramenta didática contábil parte de pesquisas como a de Marion (2011), que revela que 41\% dos discentes de Ciências Contábeis se formam no curso sem entender os conceitos de débito e crédito, e de Wall, Prado e Carraro (2008) e Pinto et al (2012), apresentando suas experiências com a utilização de metodologias ativas para ensino em sala de aula. A aprendizagem ativa ocorre quando o estudante está interagindo com o tema em estudo, e assim sendo estimulado a construir o conhecimento ao invés de recebê-lo de forma passiva, como em uma aula expositiva, e o professor passa a ser orientador dessa construção de conhecimento (BARBOSA; MOURA, 2013). Assim, a equipe se reuniu para construir a proposta inicial do projeto, seus objetivos, estabelecer critérios e definir quais seriam as estratégias para atender aos objetivos propostos.

A ferramenta teve como foco abranger o conteúdo de escrituração contábil a partir do método das partidas dobradas, demonstrando de forma dinâmica a lógica sequencial entre os conteúdos estudados previamente, como os lançamentos contábeis e seus reflexos na geração do Livro Diário, Livro Razão, Demonstração do Resultado do Exercício (DRE) e Balanço Patrimonial (BP).

É importante compreender que o aluno que programou o software, naquele momento, estava na parte final do Curso Técnico em Informática. A experiência em programação do aluno era, também naquele momento, limitada em alguns serviços e soluções de baixo custo e baixa complexidade.

A necessidade de ter uma solução em curto prazo para realização de observações de usabilidade na turma levou ao desenvolvimento de um protótipo como solução. Não foi requisitada, nesta fase inicial, a persistência dos dados em um banco de dados. Portanto, foi possível construir, via JavaScript, as funcionalidades significativas e as funções de cálculo para o protótipo.

Os conteúdos teóricos foram compilados e adequados à linguagem dos alunos a partir dos materiais didáticos selecionados previamente. A construção deveria possibilitar o acesso dos conteúdos nas quatro opções do menu.

A primeira é a "Página Inicial", que contém apresentação inicial do projeto, explicação introdutória sobre contabilidade, escrituração e o que é o software, além de forma de contato e informações gerais.

A segunda opção é a página "Quem somos", que contém informações sobre os projetos e equipe. 
A terceira opção, "Conteúdos", é dividida em páginas específicas para "Aspectos Contábeis", "Dicionário" e "Exemplo". Cada página contém informações pertinentes a contabilidade.

Em Aspectos Contábeis, há a explicação sobre partidas dobradas e livros contábeis, com links para conteúdos inerentes ao aprendizado do aluno. A página Dicionário contém a explicação de uma lista de termos da contabilidade, tais como Contas retificadoras, Provisão para Devedores Duvidosos, Duplicatas, Bens tangíveis e intangíveis, etc. Em exemplo, há a figura de uma nota fiscal e a demonstração de obtenção dos dados.

Por fim, a quarta opção do menu é "Praticando". Considerada a principal aba do software e que despendeu maior tempo no desenvolvimento, é destinada à prática dos exercícios. Nesta página, além do tutorial, são disponibilizados para os alunos 14 atividades (exercícios de escrituração contábil) que estão divididas em três níveis de dificuldade (moleza, moderado e hard), além de uma atividade livre, em que o professor possa fazer seu próprio exercício e utilizar o software com seus alunos de acordo com suas necessidades.

Os exercícios/atividades podem ser acessados de maneira aleatória sem a exigência de execução de atividade prévia. A opção do grau de dificuldade também é opcional. É possível que o aluno corrija os lançamentos indefinidamente sem que haja o trancamento do lançamento. A mesma opção é dada para gerar o Balanço Patrimonial e a Demonstração do Resultado do Exercício.

Há possibilidade de abertura dos razonetes (contas T) e incrementos de linhas para lançamentos e acesso ao plano de contas. Esse plano ajuda o aluno no momento da realização do lançamento tendo em vista a visualização do nome das contas e a opção de escolha das mesmas.

A opção da calculadora instalada no protótipo também possibilita a verificação de erro ou acerto a cada novo lançamento. Outra solução são os ícones explicativos adicionados ao símbolos (D/C) débito e crédito, os quais possibilitam que os alunos relembrem os conceitos a eles atribuídos.

\section{Impactos e resultados}

O software foi utilizado por turmas do curso Técnico em Administração Integrado ao Ensino Médio. Antes de utilizar a ferramenta no laboratório de informática, os alunos foram iniciados no conteúdo de escrituração contábil, de modo tradicional, em sala de aula, com lápis e caderno.

$\mathrm{Na}$ sequência, as aulas sobre escrituração contábil foram realizadas no laboratório de informática do campus e as atividades realizadas a partir da utilização do software. A atividade foi caracterizada como um instrumento adicional de apoio ao processo de ensino e aprendizagem de contabilidade.

Inicialmente, na primeira etapa do projeto, foi elaborado um questionário no qual foram coletados alguns relatos de alunos, que evidenciaram algumas vantagens de utilização do software, como fácil identificação de erro nos lançamentos, maior assertividade na escolha das contas por conta do acesso ao plano de contas estruturado. 
Os alunos também perceberam uma melhora na organização dos razonetes, o que possibilitou um avanço no raciocínio lógico do conteúdo, uma vez que tal organização possibilita a visualização da trajetória dos lançamentos contábeis. Tais elementos são indícios de que a ferramenta tecnológica pode ser uma estratégia profícua no processo de ensino aprendizagem.

$\mathrm{Na}$ segunda etapa do projeto foi elaborada uma nova metodologia de avaliação, na qual foram utilizadas como estudo duas turmas do curso Técnico em Administração Integrado ao Ensino Médio da mesma instituição de ensino. Enquanto uma das turmas continuou com as aulas tradicionais de contabilidade, a outra teve aulas no laboratório e utilizou a ferramenta para resolução dos exercícios, complementando o ensino inicial em sala de aula e exercendo o papel de grupo experimental. Foi utilizada como avaliação da nova metodologia comparação de desempenho entre as duas turmas, o qual trouxe como resultados uma melhora nas notas dos discentes do grupo experimental em comparação com a turma que continuou com aulas tradicionais. Todavia, entende-se que "não se pode reduzir o processo de ensino e aprendizagem apenas à "cultura das boas notas', já que nem sempre a boa nota revela a verdadeira aprendizagem". (ZENORINI; SANTOS; MONTEIRO, 2011).

O êxito do software demonstrou a necessidade e a oportunidade de reescrita do software com a utilização de recursos mais modernos, robustos e aprimorados, a exemplo de um Framework MVC (Model-View-Controller) e do aprimoramento da experiência do usuário e funcionalidades disponibilizadas para eles.

Algumas das funcionalidades desejadas são: a persistência dos exercícios realizados e de múltiplas versões destes; um modo de correção online com feedback de um ou mais professores de contabilidade; cálculo dinâmico dos razonetes; utilização de recursos visuais de ajuda; compartilhamento dos exercícios entre usuários; criação de turmas; e tutoria online. A equipe já está trabalhando em uma nova versão do software.

As análises realizadas pela equipe do projeto durante a utilização do software revelaram que a ferramenta é válida como uma estratégia complementar de aprendizagem, tendo em vista principalmente os depoimentos dos alunos e o maior interesse pela disciplina após a implementação da ferramenta.

No entanto, não é possível afirmar que a aprendizagem dos alunos tenha sido maior ou melhor em relação às atividades desenvolvidas em sala de aula devido a poucas pesquisas realizadas. Para buscar elementos que indicassem tal evolução seriam necessárias outras estratégias avaliativas vinculadas ao processo e ao projeto.

\section{Considerações finais}

A inserção de estratégias tecnológicas na sala de aula tem sido amplamente discutida por especialistas da área da educação. Uns, os mais adeptos às tecnologias, admitem sua importância, outros, os mais resistentes, ainda se questionam do suposto potencial benéfico das tecnologias em sala de aula.

Nesse sentido, experiências como a narrada poderão servir de memória para que possamos avaliar, a partir de nossas práticas em sala de aula o sentido e os resultados das tecnologias na construção de conhecimento. 
Em outras palavras, ao resgatarmos elementos dessa trajetória, bem como das interações nas aulas tradicionais e nos laboratórios, reavaliando o processo do que foi feito, para quem foi feito, quais os resultados ao longo desse percurso, é também buscar um reposicionamento do nosso ser enquanto sujeito epistêmico - conhecedor - e que está em constante transformação. Esse reposicionamento, enquanto professor, inclui sobremaneira, ajudar os alunos a descobrirem a abordagem de aprendizagem que, para eles, tenha o maior sentido, seja ela tradicional - lápis caneta ou através de tecnologia digital.

Uma coisa é certa. Os novos modos de viver, delineados pela penetrabilidade (CASTELLS, 2008, p.68) das tecnologias, nos obrigam, professores e alunos, a pensar em estratégias de ensino e de aprendizagem que permitam a utilização do potencial tecnológico na produção de conhecimentos.

\section{Referências}

BARBOSA, Eduardo Fernandes; MOURA, Dácio Guimarães de. Metodologias Ativas de Aprendizagem na Educação Profissional e Tecnológica. B. Tec. Senac, Rio de Janeiro, v. 39, n. 2, p. 48-67, mai./ago. 2013. Disponível em: $<$ http://www.bts.senac.br/index.php/bts/article/view/349/333>. Acesso em: 15 set. 2019.

CASTELLS, Manuel. A sociedade em rede. A era da informação: economia, sociedade e cultura; v.1. Tradução Roneide Venâncio Majer. $6^{\circ}$ ed. São Paulo. Paz e Terra, 1999.

CLANDININ, D. Jean; CONNELLY, F. Michael. Pesquisa narrativa: experiência e histórias na pesquisa qualitativa. Tradução: Grupo de Pesquisa Narrativa e Educação de Professores ILEEL/UFU. Uberlândia: Edufu, 2011.

MARION, José Carlos. Contabilidade Empresarial. 9ª ed. São Paulo: Atlas, 2011.

PINTO, Antônio Sávio da Silva et al. Inovação Didática - Projeto de Reflexão e Aplicação de Metodologias Ativas de Aprendizagem no Ensino Superior: Uma Experiência com "Peer Instruction". Janus, Lorena, v. 9, n. 15, p. 75-87, jan./jul. $2012 . \quad$ Disponível em: $<$ http://unifatea.com.br/seer3/index.php/Janus/article/view/289/260>. Acesso em: 22 set. 2019.

WALL, Marilene Loewen; PRADO, Marta Lenise do; CARRARO, Telma Elisa. A experiência de realizar um Estágio Docência aplicando metodologias ativas. Acta paul. enferm., São Paulo, v. 21, n. 3, p. 515-519, 2008. Disponível em: $<$ http://www.scielo.br/scielo.php?script=sci_arttext\&pid=S0103-2100200800030002 $2 \& \operatorname{lng}=$ en\&nrm=iso $>$. Acesso em: 22 set. 2019.

ZENORINI, Rita da Penha Campos; SANTOS, Acácia Aparecida Angeli dos; MONTEIRO, Rebecca de Magalhães. Motivação para aprender: relação com o desempenho de estudantes. Paidéia (Ribeirão Preto), Ribeirão Preto, v. 21, n. 49, p. 157-164, Ago. 2011. Disponível em: $<\mathrm{http}: / /$ www.scielo.br/scielo.php?script=sci_arttext\&pid=S0103-863X20110002000 03\&lng=en\&nrm=iso $>$. Acesso em: 22 set. 2019. 